\title{
Intoxicação por etanol em bovinos alimentados com bagaço de malte acrescido de levedura de cerveja ${ }^{1}$
}

\author{
Janzel G. Trujillo², Maria Audiléia S. Teixeira², Adrielli Heloise A. Lima², \\ Daniele P. Montão ${ }^{2}$, Talita B. Ross² ${ }^{2}$ Gabriela Riet-Correa², Valíria D. Cerqueira ${ }^{2 *}$ \\ e Pedro S. Bezerra Júnior ${ }^{2}$
}

\begin{abstract}
Trujillo J.G., Teixeira M.A.S., Lima A.H.A., Montão D.P., Ross T.B., Riet-Correa G., Cerqueira V.D. \& Bezerra Júnior P.S. 2018. [Ethanol poisoning in cattle fed with malted barley waste with brewer's yeast.] Intoxicação por etanol em bovinos alimentados com bagaço de malte acrescido de levedura de cerveja. Pesquisa Veterinária Brasileira 38(3):382-386. Instituto de Medicina Veterinária, Universidade Federal do Pará, BR-316 Km 61, Bairro Saudade, Castanhal, PA 68746-360, Brazil. E-mail: valiriavet@gmail.com

An outbreak of ethanol poisoning that affected a dairy cattle herd fed with the brewery by-product known as malt bagasse, wet brewery residue, malted barley waste or "barley". The outbreak began about 24 hours after a new product of the by-product was offered to cattle that had an alcoholic odor. Chromatographic and microbiological analysis of this by-product sample confirmed the presence of ethanol and Saccharomyces spp., respectively, indicating the addition of another by-product brewery, brewer's yeast or yeast. The main clinical signs observed were diarrhea, salivation, staggering gait and decubitus. Morbidity was 12.2\% (5/41) and mortality was $2.4 \%$ (1/41). A cow that died after a 3-day of clinical course was necropsied. No significant macroscopic lesions were observed, but in the histopathology, there was acute, multifocal, moderate necrosupurative rumenitis with secondary bacterial and fungal colonization, indicating concomitant ruminal acidosis. In the chromatographic analysis of samples of rumen and liver contents of this bovine, variable amounts of ethanol were detected. The data from the present study indicate that the possibility of ethanol intoxication should be considered in cattle with neurological and digestive signs fed with RUC when added to brewer's yeast.

INDEX TERMS: Cattle, ethyl alcohol, beer yeast, poisoning, barley, by-products, toxicoses.
\end{abstract}

RESUMO.- 0 presente trabalho descreve um surto de intoxicação por etanol que afetou um rebanho bovino de aptidão leiteira alimentado com o subproduto de cervejaria denominado bagaço de malte, resíduo úmido de cervejaria (RUC), resíduo de cevada maltada ou simplesmente "cevada". O surto iniciou cerca de 24 horas após ao fornecimento de uma nova partida do subproduto que apresentava odor alcoólico. Análise cromatográfica e microbiológica de amostra deste subproduto confirmou a presença de etanol e Saccharomyces spp., respectivamente, indicando a adição de outro subproduto de cervejaria, a levedura de cerveja ou levedo. Os principais

\footnotetext{
${ }^{1}$ Recebido em 23 de fevereiro de 2017.

Aceito para publicação em 24 de abril de 2017.

${ }^{2}$ Programa de Pós-graduação em Saúde Animal na Amazônia, Laboratório de Patologia Animal, Instituto de Medicina Veterinária, Universidade Federal do Pará (UFPA), BR-316 Km 61, Bairro Saudade, Castanhal, PA 68746-360, Brasil. *Autor para correspondência: valiriavet@gmail.com
}

sinais clínicos observados foram diarreia, salivação, andar cambaleante e decúbito. A morbidade foi de 12,2\% (5/41) e mortalidade de 2,4\% (1/41). Uma vaca que morreu após um curso clínico de 3 dias foi necropsiada. Não foram observadas lesões macroscópicas significativas, mas na histopatologia havia rumenite necrosupurativa aguda, multifocal, moderada, com colonização bacteriana e fúngica secundária, indicando acidose ruminal concomitante. Em análise cromatográfica de amostras de conteúdo ruminal e fígado deste bovino foram detectadas quantidades variáveis de etanol. Os dados do presente estudo indicam que a possibilidade de intoxicação por etanol deve ser considerada em bovinos com sinais neurológicos e digestivos alimentados com RUC quando a este acrescentado levedura de cerveja.

TERMOS DE INDEXAÇÃO: Bovino, álcool etílico, levedo de cerveja, intoxicação, cevada, subprodutos, toxicoses. 


\section{INTRODUÇÃo}

A indústria cervejeira no Brasil tem crescido nos últimos anos e, atualmente, o país é o terceiro maior produtor de cerveja no mundo, produzindo 14 bilhões de litros anuais, apenas atrás da China e dos Estados Unidos (Sebrae 2014). No estado do Pará, existem quatro cervejarias que produzem anualmente cerca de 304 milhões de litros de cerveja (IBGE 2013, MAPA 2014). A atividade gera diversos subprodutos que podem ter grande impacto ambiental se indevidamente descartados. 0 principal subproduto é o resíduo úmido de cervejaria (RUC), também denominado bagaço de malte, bagaço de cevada, resíduo de cevada maltada ou simplesmente "cevada". Outro importante subproduto é a levedura de cerveja, também chamada levedo de cerveja ou apenas levedo (Santos \& Ribeiro 2005, Thiago et al. 2014, Brust et al. 2015).

No Brasil, a maioria das cervejarias adquire o malte de terceiros e executam as três etapas principais subsequentes: (1) preparo do mosto, (2) processo fermentativo e (3) acabamento da cerveja. 0 resíduo úmido de cervejaria (RUC) é obtido após o preparo do mosto e o levedo de cerveja é gerado na segunda etapa quando a levedura acrescentada ao mosto é descartada. Assim, o RUC normalmente não possui etanol, uma vez que as leveduras são introduzidas em uma etapa posterior a sua geração (Santos \& Ribeiro 2005, Thiago et al. 2014).

Devido a suas características nutricionais e ao relativo baixo custo estes subprodutos são amplamente utilizados na alimentação animal. Assim, além de reduzir os custos da produção animal, esta utilização auxilia, ainda que indiretamente, na redução do impacto ambiental das indústrias cervejeiras (Souza 2004). No entanto, a utilização de forma empírica pelos proprietários e o armazenamento inadequado dos subprodutos têm sido associadas a diversos distúrbios em animais, como acidose ruminal, laminite, botulismo e as intoxicações por Aspergillus clavatus e etanol (Brust et al. 2015).

Há poucos relatos da intoxicação por etanol em bovinos (Abe et al. 1971, Wijayasinghe et al. 1984, Hibbs et al. 1986, Bruning \& Yokoyama, 1988, Humphreys 1988, Stöber 2005, Peixoto et al. 2011) e os casos descritos no Brasil têm sido relacionados a ingestão direta do levedo de cerveja disponibilizado por cervejarias no estado do Rio de Janeiro (Peixoto et al. 2011).

A intoxicação por etanol em bovinos se caracteriza clinicamente por sinais neurológicos, digestivos e cardiorrespiratórios (Abe et al. 1971, Wijayasinghe et al. 1984, Hibbs et al. 1986, Bruning \& Yokoyama 1988, Humphreys 1988, Stöber 2005, Peixoto et al. 2011). Os sinais clínicos iniciam de trinta minutos (Peixoto et al. 2011) a duas horas (Wijayasinghe et al. 1984) após a ingestão. Há uma fase de excitação seguida por uma fase depressiva que pode evoluir para a morte (Hibbs et al. 1986, Stöber 2005). Os achados de necropsia são escassos, há relatos de um odor alcoólico no conteúdo ruminal, além de timpanismo, hiperemia na mucosa ruminal, hemorragias na mucosa do abomaso e na serosa do rúmen, e congestão em diversos órgãos (Abe et al. 1971, Stöber 2005, Brust 2011). Para confirmação do diagnóstico de intoxicação por etanol em bovinos tem sido realizada a sua detecção no sangue (Wijayasinghe et al. 1984). A dosagem do etanol nos tecidos é incomum, mas tem sido empregada para diagnostico da intoxicação em humanos (Jenkins et al. 1995, Kugelberg \& Jones 2007).
O presente trabalho tem por objetivo descrever os aspectos clínico-patológicos da intoxicação por etanol pela ingestão do RUC utilizado na alimentação de bovinos leiteiros no estado do Pará, além dos níveis de etanol em amostras do RUC e do conteúdo ruminal e fígado de um bovino submetido à necropsia.

\section{MATERIAL E MÉTODOS}

Os dados clínicos e epidemiológicos foram obtidos em visita a uma propriedade leiteira localizada no município de Paragominas, região sudeste do Estado do Pará. Foi realizada a necropsia de um bovino, sendo coletados fragmentos de diversos tecidos, fixados em formalina tamponada a 10\%. Após a fixação, o material foi clivado, desidratado em álcool etílico, diafanizado em xilol e incluído em parafina. Fragmentos foram cortados a $5 \mu \mathrm{m}$ para coloração com hematoxilina e eosina (HE) e, no caso do rúmen, também pela técnica da reação pelo ácido periódico de Schiff (PAS).

Amostras do RUC utilizado, retirado diretamente do local de armazenamento na propriedade, de fígado e de conteúdo ruminal de um bovino submetido à necropsia foram coletadas e mantidas sob refrigeração até o envio a um laboratório particular para análise do teor de etanol utilizando a técnica de cromatografia em fase gasosa (headspace). Amostras do RUC do local de armazenamento na propriedade foram também enviadas ao Laboratório de Microbiologia da UFPA para isolamento e caracterização microbiológica de levedura do gênero Saccharomyces. Para tal, a amostra foi inicialmente semeada em placas contendo meio YPD (Yeast Peptone and Dextrose) e incubada com binômio tempo e temperatura adequados, posteriomente foram analizadas a morfologia e crescimento das colônias.

\section{RESULTADOS}

A propriedade possuía um plantel de 40 vacas em lactação, com idade entre 36 e 48 meses. A alimentação se constituía de pastagem e uma mistura contendo RUC. 0 proprietário relatou que comprava o RUC de uma cervejaria em Belém, a cada 30 dias. Todos os dias, ao final da tarde, era administrado aos animais $500 \mathrm{~kg}$ de RUC, adicionado de $8 \mathrm{~kg}$ de cloreto de sódio (sal comum) e 1.000 litros de água, numa proporção de $10 \mathrm{~kg} /$ animal. Ainda, segundo o proprietário, o RUC durava em torno de 30 dias após chegar à fazenda, mas que os animais ficaram 24 horas sem o alimento que havia acabado. Os animais receberam a nova partida do RUC associada ao adoecimento no mesmo dia em que esta chegou à propriedade, demonstrando avidez dos animais pelo alimento.

Na propriedade, o RUC era armazenado em silo tipo trincheira com revestimento de alvenaria e cobertura metálica, e apresentava, no momento da visita, forte odor alcoólico.

Após 24 horas do fornecimento do alimento quatro vacas adultas apresentaram diarreia, salivação, andar cambaleante, ficando em decúbito. Após 48 horas da administração, o touro da propriedade também ficou em decúbito. No terceiro dia, uma das vacas com sinais clínicos amanheceu morta. A necropsia foi realizada ao final da tarde, sendo observada putrefação moderada dos tecidos.

Na histologia do rúmen observou-se tumefação dos queratinócitos, vacuolização citoplasmática com evolução para lise, formação de vesículas e pústulas na mucosa (Fig.1). Havia, ainda, colônias bacterianas e hifas PAS positivas associadas a infiltrado inflamatório com predominância de polimorfonucleares (Fig.2). 


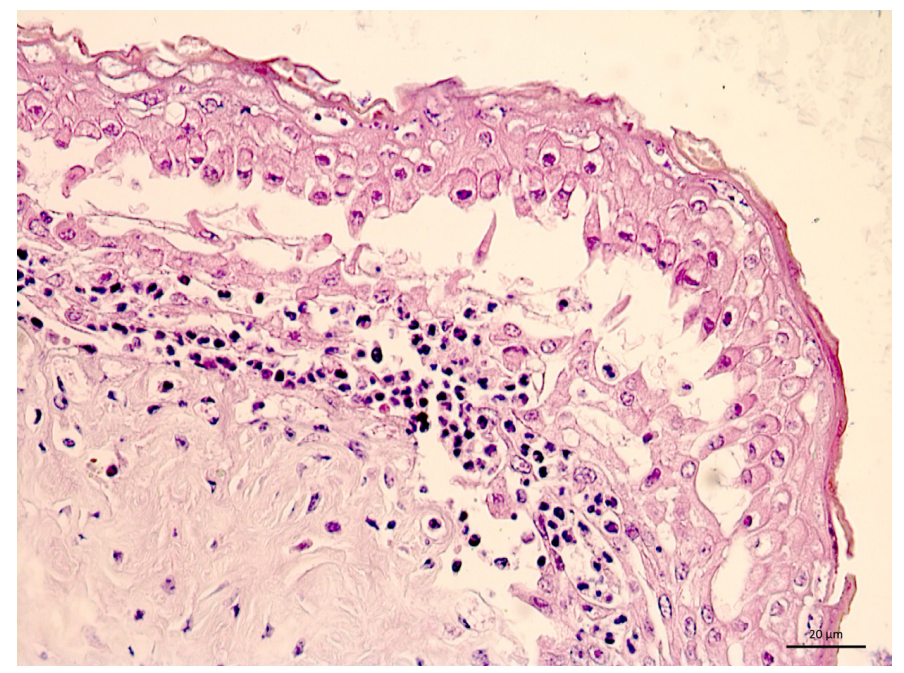

Fig.1. Intoxicação por etanol em bovinos alimentados com resíduo úmido de cervejaria. Rúmen. Degeneração hidrópica de queratinócitos com evolução para lise e formação de vesículas; notar ainda infiltrado inflamatório na submucosa subjacente. HE, obj.40x.

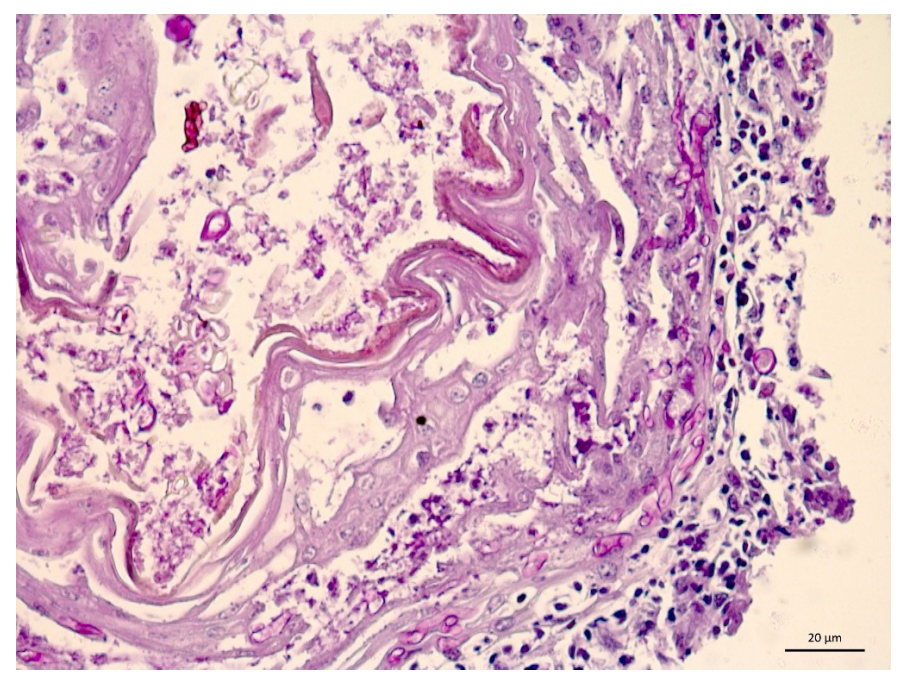

Fig.2. Intoxicação por etanol em bovinos alimentados com resíduo úmido de cervejaria. Colonização secundária das lesões ruminais. Observar na camada basal da mucosa estruturas alongadas com paredes rosadas (PAS positivas) compatíveis com hifas de fungos, nas camadas intermediárias grumos basofílicos indicando colônias bacterianas e na submucosa infiltrado inflamatório. PAS, obj.40x.

As amostras do RUC, conteúdo ruminal, e fígado revelaram níveis de álcool de $830 \mathrm{mg} / \mathrm{dl}, 125 \mathrm{mg} / \mathrm{dl}$ e $80 \mathrm{mg} / \mathrm{dl}$, respectivamente. $\mathrm{Na}$ análise microbiológica da amostra do RUC foi isolado Saccharomyces spp.

A amostra do RUC, do local de armazenamento na propriedade, nas provas microbiológicas convencionais apresentou morfologia macroscópica e microscópica compatível com o gênero Saccharomyces.

\section{DISCUSSÃO}

O diagnóstico de intoxicação por etanol em bovinos associado ao consumo do bagaço de malte no presente estudo foi inicialmente baseado na evidência circunstancial do surto quando da introdução da nova partida do subproduto na alimentação do rebanho e no odor alcoólico do mesmo. Os resultados das análises microbiológica e cromatográfica de amostras do bagaço de malte demonstraram a presença de Saccharomyces spp. e etanol, indicando a adição de outro subproduto conhecido como levedura ou levedo de cerveja e confirmando a intoxicação por etanol no presente caso.

A amostra do bagaço de malte apresentou um teor alcoólico relativamente baixo $(830 \mathrm{mg} / \mathrm{dl})$ quando comparado com o teor alcoólico do levedo de cerveja associado a intoxicação em outros relatos (Peixoto et al. 2011). 0 tempo entre a geração do subproduto e a coleta para cromatografia provavelmente contribuíram para esta diferença nos teores de álcool, visto que a evaporação é um fator importante na redução do risco de intoxicação (Peixoto et al. 2011). No presente trabalho o subproduto foi transportado por cerca de $300 \mathrm{~km}$ do fornecedor até a propriedade, sendo oferecido no dia da chegada. A coleta da amostra para análise ocorreu cerca de 48 horas após a chegada subproduto na propriedade. Assim, muito provavelmente os teores de álcool no momento da oferta ao rebanho fossem superiores aos identificados no momento da coleta para análise.

O RUC é gerado a partir da moagem de grãos de cevada maltada e grãos de adjuntos, como milho e arroz, utilizados para o preparo do mosto. Na etapa seguinte, após a retirada do RUC, são acrescentadas ao mosto as leveduras para o processo de fermentação que produz álcool (Santos \& Ribeiro 2005, Thiago et al. 2014). Assim, não se espera detectar no RUC leveduras de cerveja e etanol, uma vez que estes são introduzidos e produzidos, respectivamente, em uma etapa posterior. A constatação de crescimento de Saccharomyces spp. e a detecção de etanol $(0,83 \mathrm{~g} / \mathrm{dL})$ no RUC coletado na propriedade do presente estudo indica que ocorreu o acréscimo de levedo de cerveja no subproduto utilizado. Tal fato demonstra que o RUC disponibilizado na região pode conter levedo de cerveja e desta forma oferecer riscos de intoxicação por etanol.

A maioria trabalhos relativos à intoxicação por etanol em bovinos relata os níveis de sanguíneos deste (Wijayasinghe et al. 1984). No presente caso no momento da visita a propriedade não havia mais bovinos com sinais clínicos, assim a análise sanguínea não foi mais possível. Por isso, optou-se pela pesquisa de etanol no fígado e conteúdo ruminal do bovino submetido a necropsia, que demonstrou $0,08 \mathrm{~g} / \mathrm{dL}$ e $0,13 \mathrm{~g} / \mathrm{dL}$, respectivamente. No entanto, a interpretação da detecção de etanol em espécimes coletados em necropsias é complexa (Kugelberg \& Jones 2007).

Jenkins et al. (1995) avaliou a detecção de etanol no fígado de humanos e sua relação com os níveis no sangue coletado do coração. A maioria dos casos (66\%) com baixos índices sanguíneos $(<0,04 \mathrm{~g} / \mathrm{dL})$, atribuídos à decomposição, os índices hepáticos foram menores que $0,01 \mathrm{~g} / \mathrm{dL}$, com apenas uma amostra atingindo $0,06 \mathrm{~g} / \mathrm{dL}$. Já os casos com índices sanguíneos maiores $(\geq 0,04 \mathrm{~g} / \mathrm{dL})$ os índices hepáticos tiveram média de $0,53 \mathrm{~g} / \mathrm{dL}$, com valores variando de zero a $1,4 \mathrm{~g} / \mathrm{dL}$. Tendo este estudo como base, o nível hepático observado no bovino do presente estudo $(0,08 \mathrm{~g} / \mathrm{dL})$ foi considerado baixo. Uma das justificativas para valores menores no fígado em 
relação ao sangue é o metabolismo hepático. Os hepatócitos podem manter alguma atividade enzimática após a morte, assim a metabolização post-mortem de parte do etanol é possível (Jenkins et al. 1995, Kugelberg \& Jones 2007). Entretanto, também é relatada a possibilidade de produção post-mortem de etanol nos cadáveres por contaminação microbiana das vísceras e fermentação da glicose (Kugelberg \& Jones 2007). No presente caso a necropsia foi realizada aproximadamente dez horas após o a morte, estando o bovino em adiantado estado de putrefação. Assim, a possibilidade de produção de etanol post-mortem não pôde ser descartada. Desta forma, detecções de valores hepáticos baixos, como observado no bovino do presente estudo, têm pouco valor diagnóstico quando considerados isoladamente (Kugelberg \& Jones 2007). As dosagens do fígado e do conteúdo ruminal aqui apresentadas têm relevância quando consideradas em conjunto com os demais dados do estudo. Coletas de sangue da veia femural, da urina da bexiga, e do humor vítreo têm sido recomendadas para diagnóstico post-mortem da intoxicação por etanol em humanos e podem ser opções também para bovinos (Kugelberg \& Jones 2007), infelizmente não foram coletadas no presente caso.

Na propriedade onde ocorreu o surto de intoxicação por etanol, foi relatada a escassez do RUC por um período de 24 horas. Quando o resíduo foi fornecido aos animais, estes demostraram avidez no consumo o que pode ter contribuído para a intoxicação dos animais no presente surto. Brust et al. (2015) relata que a escassez do levedo de cerveja parece estimular um maior consumo e consequentemente, a intoxicação. A proximidade dos casos ocorridos com a chegada do RUC na propriedade também indica que quanto mais próximo da chegada, mais elevados os níveis de álcool, o que contribui para a intoxicação tanto nos lotes de animais já habituados ao resíduo, mas principalmente naqueles durante a fase de adaptação.

A dominância em um rebanho de bovinos se estabelece pela competição por um determinado recurso, e define qual ou quais indivíduos terão prioridade desde a água até o alimento (Costa \& Costa e Silva 2007). Na propriedade estudada, o alimento era fornecido em cocho contínuo, sem separações, para que todos os animais tivessem acesso ao mesmo tempo, o que pode ter contribuído para que os animais hierarquicamente dominantes tivessem acesso não só aos $10 \mathrm{~kg}$ fornecidos para cada animal, mas também ao que era fornecido aos outros, possibilitando uma sobrecarga ruminal de alimentos rapidamente fermentáveis, assim como um aumento na quantidade de etanol ingerida por esses animais.

Os sinais clínicos observados nos bovinos alimentados por RUC são semelhantes aos casos em bovinos intoxicados experimentalmente por etanol (Abe et al. 1971, Bruning \& Yokoyama 1988, Stöber 2005) assim como nos casos naturais de intoxicação por levedo de cerveja (Brust et al. 2015, Peixoto et al. 2015). 0 início dos sinais clínicos nos animais da propriedade diferiu do citado pela literatura que afirma que, em geral após 30 minutos (Peixoto et al. 2011) a duas horas (Wijayasinghe et al. 1984) os animais adoecem. Na propriedade acompanhada, o início dos sinais foi observado após aproximadamente 12 horas da ingestão do RUC e a morte de um dos animais ocorreu aproximadamente 6 horas após o início dos sinais, tal como foi descrito por Wijayasinghe et al. (1984).
As lesões observadas no rúmen de acidose ruminal descrita nos resultados pode estar relacionada ao potencial do RUC em diminuir os valores do $\mathrm{pH}$, o que já foi descrito por vários autores (Firkins 1997, Mertens 1997). Sabe-se que a diminuição no pH ruminal é causada principalmente pela ingestão de alimentos ricos em carboidratos rapidamente fermentáveis (Owens et al. 1998). No trabalho realizado por Stern \& Ziemer (1993) o RUC é tido como um alimento que contém grandes quantidades de amido e açúcares simples os quais produzem uma marcante mudança na população microbiana do rúmen, com alta produção de ácidos graxos voláteis (Owens et al. 1998). Quando há um aumento na velocidade de produção de AGV's a capacidade de absorção no rúmen fica comprometida tendo como resultado o acúmulo de AGV's, que promoverão a redução do pH ruminal, morte de bactérias gram-negativas e aumento de bactérias grampositivas tais como Streptococcus bovis e de Lactobacillus sp. que são bactérias capazes de produzir grandes quantidades de ácido láctico favorecendo o aparecimento da acidose ruminal (Dawson \& Allison 1988). Esses quadros graves de acidose ruminal aguda em geral cursam com incoordenação, andar cambaleante, depressão profunda, decúbito permanente com morte em poucas horas (Dirksen 1981, Underwood 1992, Dirksen 2005), sintomas muito semelhantes aos apresentados pelos animais intoxicados. Mas as lesões macro e microscópicas encontradas no rúmen são discretas, em comparação com as descritas para acidose ruminal aguda (Gelberg 2007).

Os achados de necropsia do animal que veio a morte não foram determinantes para o diagnóstico, tal como foi demonstrado no trabalho realizado por Brust (2011) onde ele descreve os achados como inconsistentes para fins de diagnóstico. 0 odor alcoólico no conteúdo dos pré-estômagos comprova apenas a ingestão do produto, porém não foi observado no presente caso devido à putrefação.

\section{CONCLUSÕES}

0 presente trabalho evidencia a necessidade de se verificar junto à indústria ou distribuidora que fornece o subproduto a possibilidade de introdução de levedo de cerveja junto ao bagaço de malte para que medidas profiláticas sejam estabelecidas.

A interrupção do fornecimento deste subproduto pode favorecer a maior ingestão do mesmo pela avidez demonstrada pelos animais, e que a readaptação dos bovinos após o restabelecimento do fornecimento do subproduto se faz necessária.

Armazenar o subproduto em uma área ventilada e aguardar alguns dias para fornecer nova partida ao rebanho a fim de favorecer a evaporação do etanol.

\section{REFERÊNCIAS}

Abe R.K., Bassette R., Morrill J.L. \& Oehme F.W. 1971. Ethanol intoxication in calves fed certain milk replacers. J. Dairy Sci. 54(2):252-257. http://dx.doi. org/10.3168/jds.S0022-0302(71)85820-4. PMid:5101989.

Bruning C.L. \& Yokoyama M.T. 1988. Characteristics of live and killed brewer's yeast slurries and intoxication by intraruminal administration to cattle. J. Anim. Sci. 66(2):585-591. http://dx.doi.org/10.2527/jas1988.662585x. PMid:3286594. 
Brust L.A.C. 2011. Intoxicação por etanol contido em "levedo de cerveja” em bovinos. Tese de Doutorado, Ciências Veterinárias, Instituto de Veterinária, Universidade Federal Rural do Rio de Janeiro, Seropédica, RJ. 68p.

Brust L.A.C., Aragão A.P., Bezerra Jr P.S., Galvão A., França T.N., Graça F.A.S. \& Peixoto P.V. 2015. Enfermidades em bovinos associadas ao consumo de resíduos de cervejaria. Pesq. Vet. Bras. 35(12):956-964. http://dx.doi. org/10.1590/S0100-736X2015001200004.

Costa M.J.R.P. \& Costa e Silva E.V. 2007. Aspectos básicos do comportamento social de bovinos. Revta Bras. Reprod. Anim. 31:172-176.

Dawson K.A. \& Allison M.J. 1988. Digestive disorders and nutricional toxicity, p.129-150 In: Hobson P.N. \& Hobson P.N. (Eds), The rumen microbial ecosystems. Elsevier Science Publisher, London, UK.

Dirksen G. 1981. Indigestiones en el bovino. Schnetztor-Verlag, Konstantz. 79p.

Dirksen G. 2005. Enfermedades de los órganos digestivos y la pared abdominal, p.25-631. In: Dirksen G., Gründer H. \& Stöber M. (Eds), Medicina Interna y Cirurgía del Bovino. Vol.1. 4ํa ed. Inter-Médica, Buenos Aires.

Firkins J.L. 1997. Effects of feeding nonforage fiber sources on site of fiber digestion. J. Dairy Sci. 80(7):1426-1437. http://dx.doi.org/10.3168/jds. S0022-0302(97)76072-7. PMid:9241605.

Gelberg H.B. 2007. Alimentary system, p.301-392. In: McGavin M.D. \& Zachary J.F. (Eds), Pathologic Basis of Veterinary Disease. 4th ed. Elsevier.

Hibbs C.M., Smith G.S., Hallford D.M., Thilsted J.P., Robb J., Trujillo P. \& Anspaugh V. 1986. Accidental and experimental ethanol toxicosis in cattle. Kongress Weltgesellschaft Buiatrik 14:733-737.

Humphreys D.J. 1988. Organic compounds III: miscellaneous, p.183-208. In: Ibid. (Ed.), Veterinary Toxicology. 3rd ed. Baillière Tindall, London. 356p.

IBGE 2013. Pesquisa Industrial. Instituto Brasileiro de Geografia e Estatística. Disponível em <http://loja.ibge.gov.br> Acessado em 15 jul. 2016.

Jenkins A.J., Levine B.S. \& Smialek J.E. 1995. Distribution of ethanol in postmortem liver. J. Forensic Sci. 40(4):611-613. http://dx.doi.org/10.1520/ JFS13835J. PMid:7595297.

Kugelberg F.C. \& Jones A.W. 2007. Interpreting results of ethanol analysis in postmortem specimens: a review of the literature. Forensic Sci. Int. 165(1):1029. http://dx.doi.org/10.1016/j.forsciint.2006.05.004. PMid:16782292.
MAPA 2014. Lista Completa de Estabelecimentos e Bebidas. Ministério de Agricultura, Pecuária e Abastecimento. Disponível em <http://www. agricultura.gov.br>

Mertens D.R. 1997. Creating a system for meeting the fiber requirements of dairy cows. J. Dairy Sci. 80(7):1463-1481. http://dx.doi.org/10.3168/jds. S0022-0302(97)76075-2. PMid:9241608.

Owens F.N., Secrist D.S., Hill W.J. \& Gill D.R. 1998. Acidosis in cattle: a review. J. Anim. Sci. 76(1):275-286. http://dx.doi.org/10.2527/1998.761275x. PMid:9464909.

Peixoto P.V., Brust L.A.C., Brito M.F., França T.N., Malafaia P. \& Tokarnia C.H. 2011. Ethanol poisoning in cattle by ingestion of waste beer yeast in Brazil, p.494-498. In: Riet-Correa F., Pfister J., Schild A.L. \& Wierenga T.L. (Eds), Poisoning by Plants, Mycotoxins, and Related Toxins. CABI, London. http:// dx.doi.org/10.1079/9781845938338.0494.

Santos M.S. \& Ribeiro F.M. 2005 Cervejas e refrigerantes. CETEB, São Paulo. 58p. Disponível em <http://www.cetesb.sp.gov.br/Tecnologia/producao_limpa/ documentos/cervejas_refrigerantes.pdf>

Sebrae 2014. Potencial de consumo de cervejas no Brasil. Serviço Brasileiro de Apoio às Micro e Pequenas Empresas. Disponível em <http://www. sebraemercados.com.br> Acessado em 15 jul. 2016.

Souza 0. 2004. Apenas 5\% dos resíduos agroindustriais alimentariam o rebanho bovino mundial. Correio Riograndense, Rio Grande do Sul. 5p.

Stern M.D. \& Ziemer C.J. 1993. Consider value, cost when selecting nonforage fiber. Feedstuffs 62:14-21.

Stöber M. 2005. Intoxicación con alcohol etílico. In: Dirksen G., Gründer H.D. \& Stöber M. (Eds), Medicina Interna y Cirugía del Bovino. Vol.2. 4aㅗ ed. Inter-Médica, Buenos Aires. 1024p.

Thiago R.S.M., Pedro P.M.M. \& Eliana F.C.S. 2014. Solid wastes in brewing process: a review. J. Brew. Distilling 5(1):1-9. http://dx.doi.org/10.5897/ JBD2014.0043.

Underwood W.J. 1992. Rumen lactic acidosis. II. Clinical signs, diagnosis, treatment, and prevention. Compend. Contin. Educ. Pract. Vet. 14:1265-1270.

Wijayasinghe M.S., Miranda M., Smith N.E., Baldwin R.L., Wijayasinghe C. \& Har S.A. 1984. A yeast related ethanol intoxication syndrome in experimental calves: prevention with nystatin. Can. Vet. J. 25(6):251-253. PMid:17422416. 